\title{
Towards an e-Publishing library service in Humanities and Social Sciences: A feasibility study
}

\author{
Rosa di Cesare ${ }^{\mathrm{a}, *}$, Silvia Giannini ${ }^{\mathrm{b}}$ and Daniela Luzi ${ }^{\mathrm{a}}$

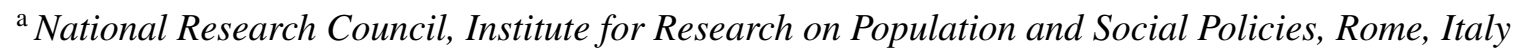 \\ ${ }^{\mathrm{b}}$ National Research Council, Institute of Information Science and Technology, Pisa, Italy
}

\begin{abstract}
The paper describes a methodology used to analyze the editorial production of CNR Institutes belonging to the Department of Humanities and Social Sciences (HSS). This analysis is considered a pre-requisite to design a feasibility study to develop an e-Publishing service tailored to HSS. To reach this aim the paper describes in particular the characteristics of currently published products defining a set of quality indicators that can help designing a future e-Publishing service.
\end{abstract}

Keywords: Editorial products, HSS, in-house and external publishing, e-Publishing services

\section{Introduction}

Academic and research libraries have had a fundamental role in supporting Open access practices, in the construction of Institutional repositories as well as in the development of digitization programs, moving towards the development of additional services for their community scholars. This is in line with the necessity of libraries reshaping their role in the digital age following changes in the scholarly communication models. In this context, library publishing services represent a new modality to produce and diffuse scholarly research outputs, improve the quality of in-house published products and decrease costs of publication $[6,12,13,19]$.

Many surveys have been promoted and/or supported by SPARC (Scholarly Publishing and Academic Resources Coalition) [7] and ARL (American Research Libraries) [3] to gain understanding of the initiatives and projects undertaken by universities and/or research institutions in the development of valueadded services to manage in-house publications. These surveys considered the advantages of using open source software to manage digital contents and pointed out critical issues in the development of these services, stressing the necessity of integrating them with other digital repositories. Case studies of successful strategies are also reported [18], highlighting the research context, type of products and/or collections to be managed with e-Publishing services. In particular many studies underline that such value-added services, generally widely experimented and used in STM (Science, Technology, Medicine) disciplinary areas, are now beginning to be discovered and used in HSS (Humanities and Social Sciences) $[1,10,11$, 14]. In fact, they represent for HSS an important and alternative channel to publish niche products or

\footnotetext{
*Corresponding author. E-mail: r.dicesare@irpps.cnr.it.
} 
native language products that commercial and traditional publishers consider risky and less profitable $[2,15,17,20,21]$.

The National Research Council (CNR) is one of the biggest Italian multidisciplinary research institutions and comprises a network of 109 geographically distributed Institutes, which have scientific and organizational autonomy. CNR editorial activity started soon after its foundation in 1923 with the publication of «Bollettino d'informazione» that contained information on research activities carried out in Italy. In 1931 this publication became «La rivista scientifica», a journal in which Enrico Fermi published his successful achievements on neutron-induced radioactivity. At local level too, CNR institutes have always created their editorial products strictly connected with their studies and research interests, tailored to different target users (general public and/or their research community) and for their production and diffusion they have made use of both conventional and non conventional channels and continue to do so.

This paper intends to describe a methodology used to analyze the editorial production of CNR Institutes belonging to the Department of Humanities and Social Sciences. This analysis is considered a pre-requisite to design a feasibility study with the aim of developing an e-Publishing service tailored to HSS characteristics. To reach this aim the paper describes in particular the characteristics of editorial products defining a set of quality criteria for current production. The result of this analysis can provide insight into the identification of weak and strong points that have to be addressed when developing a new and sustainable e-Publishing service.

\section{Survey design}

The object of our analysis is the editorial products of the CNR HSS Department published in-house and/or in collaboration with commercial publishers. Source data for the survey are Institutes' and/or commercial publishers' websites related to the editorial product description.

The first step of our analysis deals with the identification of the sample that has to meet the following criteria:

- Editorial products with a minimal set of editorial and bibliographic elements, i.e. at least an identifiable standardized series title and number,

- Current published products, i.e. the collection in which the last number/issue was published in 2008 (considering a 5 year window of publication suitable to HSS publishing model).

In this way we identified the sample to be analyzed that should represent a stable Institutes' production. Therefore, our sample is mainly formed of collections that also indicate a well-established production as well as a consolidated management in the editorial activity.

To gain insight into the characteristics of editorial products we identified a set of variables that express stability, editorial quality and visibility. These variables can be increased taking into account other characteristics, such as the composition of editorial board, presence of contribution of authors of other institutions, etc. The choice of the selected variables in our sample depends on the information available in our source of analysis, that is the Institutes' and/or publishers' websites.

In particular the variables identified to express stability are:

- Start date of publication;

- Last number/issue published;

- Number of years of publication;

- Compliance with reported publication frequency (for journals and e-journals). 
The variables identified to express the editorial quality are:

- Cover page with standardized bibliographic elements (series title and/or number, identification of the corporate source/Institution and/or Author's affiliation);

- International Bibliographic codes (ISSN; ISBN; DOI);

- Copyright/Creative commons;

- Peer-review;

- Editorial scientific board;

- Instructions for authors.

The variables identified to express the visibility are:

- Publications reported in national catalogues, i.e. National Bibliographic System (SBN) and the Italian Union Catalogue of Serials (ACNP);

- Publications indexed and/or present in international databases;

- Publications that have specific web pages to describe the editorial products;

- Modes of access to the content (full OA and partially OA).

For the purpose of our analysis the results of the survey are described distinguishing between the editorial products entirely managed in-house and those that are published and/or distributed by commercial publishers (hereafter in-house and external publishing). Moreover, results are also reported by type of editorial products (monograph series, journals and e-journals and report series) considering that each type of product has specific modes of publishing and editorial process

\section{Results}

\subsection{The characteristics of the sample}

Table 1 shows the production of the 20 CNR Institutes belonging to the HSS Department distributed by live and ceased products as well as by type of series. For the purpose of our analysis, journals are divided into traditional journals and e-journals, as the latter were one of the first products managed by e-Publishing services.

Considering live products, i.e. the sample we are going to analyze CNR Institutes publish 51 products. The majority of them are monograph series $(57.1 \%)$, followed by journals and technical report series. Interesting to note is that monographs series have a higher rate of mortality when compared with e-journals and reports that represent in our sample a well-established product. Report series are all produced by Institutes in the socio-economic disciplinary area.

Table 1

Live and ceased products by type of editorial product

\begin{tabular}{lrrrrrc}
\hline $\begin{array}{l}\text { Type of } \\
\text { editorial product }\end{array}$ & Number & $\%$ & Live & $\%$ & Ceased & $\%$ \\
\hline Monograph series & 36 & 57.1 & 26 & 72.2 & 10 & 27.8 \\
Journals & 10 & 15.9 & 8 & 80.0 & 2 & 20.0 \\
e-Journals & 9 & 14.3 & 9 & 100.0 & - & - \\
Reports & 8 & 12.7 & 8 & 100.0 & - & - \\
Total & $\mathbf{6 3}$ & $\mathbf{1 0 0 . 0}$ & $\mathbf{5 1}$ & 81.0 & $\mathbf{1 2}$ & $\mathbf{1 9 . 0}$ \\
\hline
\end{tabular}


Table 2

In-house and external publishing by type of editorial product

\begin{tabular}{lrrrrrr}
\hline Type of editorial product & Total no. & \multicolumn{2}{c}{ In-house } & & \multicolumn{2}{c}{ External } \\
\cline { 7 - 8 } & & No. & $\%$ & & No. & $\%$ \\
\hline Monograph series & 26 & 9 & 34.6 & & 17 & 65.4 \\
Journals & 8 & - & - & & 8 & 100.0 \\
e-Journals & 9 & 5 & 55.6 & & 4 & 44.4 \\
Reports & 8 & 8 & 100.0 & & - & - \\
Total & $\mathbf{5 1}$ & $\mathbf{2 2}$ & $\mathbf{4 3 . 1}$ & $\mathbf{2 9}$ & $\mathbf{5 6 . 9}$ \\
\hline
\end{tabular}

The editorial production of CNR Institutes is almost equally distributed between in-house and external publishing (Table 2). 56.9\% of them (29 out of 51) externalize part of the editorial process that is generally related to the phases of copyediting and distribution. Commercial publishers are generally in charge of providing both printed and/or electronic copies and are further responsible for membership fees and subscriptions. Our sample includes both large and small size commercial publishers. It is noteworthy that the majority of them (75.6\%) are included in the list provided by the National Agency for the Evaluation of Universities and Research Institutes (ANVUR) used in the recent evaluation exercise and this indicates the recognition of their quality.

To mention some other general characteristics of the editorial products, the language of publication is for half of them Italian, while 17.6\% are in English. In the Philosophy and Archaeology fields some issues are also in German, French and Spanish. Moreover, 8 of the in-house products are produced by handling manuscript management systems, they include all e-journals, 2 monograph series and also a report series. 3 products are managed by OJS (Open Journal System) [5].

\subsection{Stability}

To measure the longevity of products we calculated for each product the number of years starting from the first number of publication. We then grouped them into three classes: from 1 to 10 year, from 11 to 20 , more than 20 years of publication (Table 3 ). The majority of all products (40.9\% in-house products, $44.8 \%$ external publishing) were published for more than 20 years.

Note that although monograph series have a high rate of mortality (as previously shown in Table 1), the group of live ones has a long period of publication (Table 3), which is more evident in the case of in-house monograph series (44.4\% over 20 years). Considering reports, they are stable products with a high rate of continuity over time (50\% more than 20 years). The majority of e-journals are obviously younger considering both in-house and external publishing (respectively $60 \%$ and $75 \%$ are published in the interval from 1 to 10 years). Two exceptions are an archaeology journal (Archeologia e calcolatori) externally published since 2013, which however started its publication in 1990 and became an online journal in 1998. It is interesting to note that the Institute has developed locally an OAI compliant open source publishing system to manage this journal, but nevertheless recently transferred its management to a commercial publisher [16]. The other one is an in-house journal "Tecnologie didattiche", which started its publication in 1993 providing a free access to all its contents. Finally, the majority of journals and e-journals (13 out of 18) are compliant with the established frequency of the journal. 
Table 3

In-house and external publishing by number of years of publication and type of product

\begin{tabular}{lcccc}
\hline Type of editorial products & Number & \multicolumn{3}{c}{ Years of publications } \\
\cline { 3 - 5 } & & $1-10$ & $11-20$ & $>20$ \\
\hline In-house publishing & & & & \\
$\quad$ Monograph series & 5 & 44.4 & 11.1 & 44.4 \\
e-Journals & 8 & 60.0 & 20.0 & 20.0 \\
Reports & $\mathbf{2 2}$ & 12.5 & 25.0 & 50.0 \\
$\quad$ Total & & $\mathbf{3 6 . 4}$ & $\mathbf{2 2 . 7}$ & $\mathbf{4 0 . 9}$ \\
External publishing & 17 & 35.3 & 23.5 & 41.2 \\
Monograph series & 8 & 12.5 & 25.0 & 62.5 \\
Journals & 4 & 75.0 & - & 25.0 \\
e-Journals & $\mathbf{2 9}$ & $\mathbf{3 4 . 5}$ & $\mathbf{1 9 . 2}$ & $\mathbf{4 4 . 8}$ \\
$\quad$ Total & & &
\end{tabular}

\subsection{Editorial quality}

Editorial quality can be considered under different points of view [8,9]. One of them is represented by formal aspects that include a specific cover page that makes the editorial products univocally identifiable under a recognizable brand and that contains all bibliographic elements in a standardized way. Another aspect of the editorial quality pertains the selection, coherence and assessment of contents to be published, which are generally managed by the peer-review process. These aspects are differently applied according to the type of editorial product. Journal articles are subject to a consolidated peer-review process, while in case of monographs an editorial board may select contents and/or appoint a reading committee to evaluate the quality of books.

Moreover, other types of products such as reports - traditionally in-house scientific publications, the so-called Grey Literature - may have an internal peer-review or no review at all as well as a no standardized presentation of bibliographic elements. For the purpose of our analysis we considered important to track the copyright/CC attributions especially in the case of in-house editorial products, because such an explicit declaration is in our opinion an indication of the awareness on the part of the producers that demonstrate having a clear policy on the diffusion of contents as well as on its protection. When the editorial products are published in collaboration with commercial publishers, our intent was to explore whether changes introduced by Creative commons or Open access have influenced the attribution of the intellectual property of both content producers and commercial publishers. However, it is difficult to obtain information on the type of contract agreed upon, that may vary also in a single title of the same monograph series. When the commercial publisher did not clearly indicate the copyright assignment to the entire series and no other information was available in the Institute's website, we assigned copyright of the entire series to the commercial publishers.

Table 4 shows the results of the analysis of the set of selected attributes that characterize editorial quality. Considering in-house products, cover page with the basic bibliographic elements as well as International standard codes are present in almost all editorial products. Only reports, as expected, have values with high variability.

Differences are more evident considering the attributes of the right side of the table that tend to have minimum values in all types of products. $50 \%$ of editorial in-house products (11 out of 22$)$ clearly assign 
Table 4

In-house and external publishing by type of editorial product

\begin{tabular}{lrrrrrrr}
\hline Type of editorial products & Number & $\begin{array}{c}\text { Cover } \\
\text { page }\end{array}$ & $\begin{array}{c}\text { International } \\
\text { standard } \\
\text { codes }\end{array}$ & $\begin{array}{c}\text { Copyright/ } \\
\text { Licensing }\end{array}$ & $\begin{array}{c}\text { Instructions } \\
\text { for author }\end{array}$ & $\begin{array}{c}\text { Peer } \\
\text { review }\end{array}$ & $\begin{array}{c}\text { Scientific } \\
\text { editorial } \\
\text { board }\end{array}$ \\
\hline $\begin{array}{l}\text { In-house publishing } \\
\text { Monograph series }\end{array}$ & 9 & 88.9 & 100.0 & 55.6 & 22.2 & 22.2 & 33.3 \\
e-Journals & 5 & 100.0 & 80.0 & 60.0 & 33.3 & - & 80.0 \\
Reports & 8 & 62.5 & 62.5 & 37.5 & 11.1 & 25.0 & 37.5 \\
Total & $\mathbf{2 2}$ & $\mathbf{8 1 . 8}$ & $\mathbf{8 1 . 8}$ & $\mathbf{5 0 . 0}$ & $\mathbf{2 7 . 7}$ & $\mathbf{1 8 . 2}$ & $\mathbf{4 5 . 5}$ \\
External publishing & & & & & & & \\
$\quad$ Monograph series & 17 & 100.0 & 100.0 & 100.0 & 88.2 & 23.5 & 52.9 \\
Journals & 8 & 100.0 & 100.0 & 100.0 & 87.5 & 75.0 & 100.0 \\
e-Journals & 4 & 100.0 & 75.0 & 100.0 & 100.0 & $\mathbf{7 5 . 0}$ & 100.0 \\
$\quad$ Total & $\mathbf{2 9}$ & $\mathbf{1 0 0 . 0}$ & $\mathbf{9 6 . 6}$ & $\mathbf{1 0 0 . 0}$ & $\mathbf{8 9 . 7}$ & $\mathbf{4 4 . 8}$ & $\mathbf{7 2 . 4}$ \\
\hline
\end{tabular}

an intellectual protection to their publications and this tendency is more evident in newborn publications such as e-journals ( 3 out of 5). Note that most of them are published under the Creative commons license combining both intellectual protection and the willingness to share their scientific products. In one case the products are licensed by CC-by, the others are licensed by CC-by-NC-ND.

When considering the selection of content, the tendency is to have an editorial board more frequently than peer-review, and this is more evident considering e-journals. In the case of monograph series, 2 have both peer-review and an editorial board. Similarly and surprisingly, reports too are subject to content evaluation, with 2 report series having both peer-review and an editorial board.

Instructions for authors that indicate a certain attention to the layout and structuring of contents are quite rare in all types of in-house editorial products. Of course, we cannot exclude that each Institute has its editorial guidelines informally diffused among its internal scientific content providers.

If we compare these results with products published in collaboration with commercial publishers, there is a higher level of presence of attributes related to editorial quality (cover page, international standards codes and instructions for authors). Moreover, there is no evident variability among products, if we exclude the attribute of peer review. As expected, the peer review process is carried out more frequently in journals and e-journals, where all of them also have an editorial board. Conversely, $52.9 \%$ of monograph series have an editorial board, and only a few of them are subject to peer-review. Considering that the externalized editorial activities are generally connected with the distribution phase of the editorial process, we cannot exclude that content selection is carried out in-house. However, given the importance of monographs in HSS and considering that peer-review is one of the main assessment criteria in the context of the National Evaluation Exercise, we would expect that a clear indication of a peer review process would be mentioned either in the Institutes' or in the publishers' web pages.

Considering the attribute related to the protection of the intellectual property, almost all external published products have the copyright transferred to the commercial publishers, while only one e-journal has a CC-by-NC-ND attribution. In the HSS field subsidy model of publication is widely diffused in particular for monographs as they usually represent niche products. Moreover, the majority of these products often clearly cite Institutes as the scientific editor and sometimes also report the CNR logo. 
In the context of Open access and considering the various possibilities offered by $\mathrm{CC}$ for the diffusion of scientific contents, we think that there should be more care in the policy of transferring copyright [4].

\subsection{Visibility}

The indicator of visibility gives an indication of how scientific contents are diffused and easily disclosed (Table 5). Therefore to measure this indicator we considered the presence of the editorial products in national catalogues (in our case SBN and ACNP), whether they are indexed in international databases, or whether they are described in a specific webpage. Moreover, we verified whether they are freely available. All these elements are proved to increase the possibility of being cited.

Considering the entire sample, 24 editorial products out of 51 are indexed, 12 of them are retrievable in Google Scholar, while the others are also reported in international databases such as SSCI, Scopus and/or in international specialized archives such as ERIH (European Reference Index for the Humanities) and RePEc (Research Papers in Economics). Moreover, it is interesting to note that there is a positive relationship between longevity and presence in international databases. Among the 14 products indexed in international databases, half were published for more than 20 years, while the others are young products (1-10 years).

When considering the external publishing products, they have obviously a higher level of presence in national catalogues $(88.2 \%)$, while the presence in international databases is not so prevalent especially for monograph series (29.4\%). A consistent number of in-house monograph series are present in national catalogues $(77.8 \%)$, and one third of all products (36.4\%) are indexed in international databases. Monographs series are more frequently indexed in international databases than external published monographs series. Reports turned out to be stable products with a high number of years of publication (cf. Table 3) and are also indexed in disciplinary archives such as RePEc.

Considering web pages, the majority of products are described in a specific webpage and there are no differences between in-house and external publishing with the exception of in-house monographs series (100\% vs. $82.4 \%$ ). Remarkable differences emerge when considering the access to contents: the majority of in-house e-journals and report series are freely available, while only one third of in-house monograph series are open access. Conversely, the great majority of external products are not open access.

Table 5

In-house and external publishing by type of editorial product

\begin{tabular}{lcccccc}
\hline Type of editorial product & Number & $\begin{array}{c}\text { National } \\
\text { catalogue }\end{array}$ & $\begin{array}{c}\text { International } \\
\text { database }\end{array}$ & Webpage & $\begin{array}{c}\text { Open } \\
\text { access }\end{array}$ & Partially OA \\
\hline $\begin{array}{l}\text { In-house publishing } \\
\text { Monograph series }\end{array}$ & 9 & 77.8 & 33.3 & 100.0 & 33.3 & 11.1 \\
e-Journals & 5 & - & 40.0 & 100.0 & 80.0 & - \\
Reports & 8 & 25.0 & 37.5 & 50.0 & 62.5 & 25.0 \\
Total & $\mathbf{2 2}$ & $\mathbf{4 0 . 9}$ & $\mathbf{3 6 . 4}$ & $\mathbf{8 6 . 4}$ & $\mathbf{5 4 . 5}$ & $\mathbf{1 3 . 6}$ \\
External publishing & & & & & & \\
Monograph series & 17 & 88.2 & 29.4 & 82.4 & 5.9 & 11.8 \\
Journals & 8 & 100.0 & 100.0 & 100.0 & - & - \\
$\quad$ e-Journals & 4 & 100.0 & 75.0 & 100.0 & 50.0 & - \\
$\quad$ Total & $\mathbf{2 9}$ & $\mathbf{9 3 . 1}$ & $\mathbf{5 5 . 2}$ & $\mathbf{8 9 . 7}$ & $\mathbf{1 0 . 3}$ & $\mathbf{6 . 9}$ \\
\hline
\end{tabular}




\section{Conclusions}

The editorial activity is a fundamental component of scholarly communication for the diffusion of research results and is currently undergoing important changes due to the widespread adoption of digital publishing technologies as well as to an increasing acceptance of Open access publication models. Many scientific institutions are developing their own e-Publishing services, generally supported by libraries, to enhance diffusion and quality and reduce costs. To design e-Publishing services it is necessary to gain insight into the organizational-productive context in terms of type and consistency of the core editorial products, currently adopted business model as well as stakeholders involved in the process.

Our survey has privileged the first two aspects, focusing on the type of editorial products managed by CNR Institutes in the area of HSS and analyzing the business model adopted (in-house and external publishing). Summing up our results, CNR Institutes in HSS produce different types of editorial products in a stable way and with continuity over time. There is a consistent number of series that have published for more than 20 years and the editorial activity is keeping pace with newborn products that also include e-journals. No major differences emerged in the editorial quality of in-house and external products, especially if we consider formal editorial aspects. The selection of content depends on the type of products; external published monograph series prevalently have scientific editorial boards, while peerreview is more frequent for journals and e-journals. Content evaluation of in-house publishing is not so widespread for any type of editorial product. The introduction of an e-Publishing service could support the peer-review process more efficiently, thereby making informal procedures of content selection that may be already curried out internally, more transparent. Copyright and licensing are crucial issues for the diffusion and sharing of scientific results. In our sample there is no clear policy, especially considering the range of possibilities that are currently available to negotiate with commercial publishers. Only half of in-house products have a clear attribution of the intellectual property, while copyright of external publishing is always transferred to the commercial publishers. Considering that most monograph series are generally subsidized especially in the area of HSS, the adoption of an e-Publishing service could trigger a more flexible management and fruitful cooperation with publishers, distinguishing for instance the rights on printed copies from digital versions. E-Publishing services can also improve visibility thanks to the additional services embedded in their platform that support all the activities connected with the content exposure and retrieval in indexing and abstracting services.

In the future we intend to further analyze the organization context where editorial activities are managed carrying out a questionnaire-based survey to explore the role of libraries and/or other stakeholders involved in this process as well as researchers' needs when publishing their results.

\section{References}

[1] J. Adema, Overview of Open access models for eBooks in the Humanities and Social Sciences, OAPEN 2010, available at: http://www.aupress.ca/documents/OpenAccessModels_OAPEN.pdf.

[2] M. Alenius, Open access, University press, and editorial responsibility, Conference paper at the Workshop on Open access, 23-24 April 2007, available at: http://www.mtp.hum.ku.dk/cgibin/PDFmedopenaccess/Open_Access_Univer_0_0_ 9788763510868.pdf.

[3] Association of American University Presses, Sustaining scholarly publishing: new business models for University presses, 2011, available at: http://digital-scholarship.org/digitalkoans/2011/03/07/sustaining-scholarly-publishing-new-businessmodels-for-university-presses/.

[4] F. Bastos, S. Vidotti and N. Oddone, The University and its libraries: reaction and resistance to scientific publishers, in: ELPUB 2012. Social Shaping of Digital Publishing: Exploring the Interplay Between Culture and Technology, 16th International Conference on Electronic Publishing, ELPUB, Guimaraes, Portugal, 14-15 June 2012, available at: http://www.architexturez.net/doc/109cc66d-ef70-489e-8e0e-e75c52bd3166. 
[5] E.D. Brian and J. Willinsky, A survey of the scholarly journals using Open Journal Systems, Scholarly and Research Communication 1 (2010), 1-22.

[6] L. Brown, R. Griffiths and M. Rascoff, University publishing in a digital age, Ithaka, NY, 2007, available at: http://www.sr. ithaka.org/research-publications/university-publishing-digital-age.

[7] R. Crow, Campus-based publishing partnerships: a guide to critical issues, SPARC, Washington, DC, 2009, available at: http://www.arl.org/sparc/bm doc/pub_partnerships_v1.pdf.

[8] P. De Castro (Ed.), Training in scientific writing and open access publishing: the NECOBELAC project experience in Europe and Latin America, Istituto Superiore di Sanità Rapporti ISTISAN 12/26, Roma, 2012.

[9] DINI Certificate Document and Publication Services, Working group Electronic publishing, available at: http://edoc.huberlin.de/series/dini-schriften/2010-3-en/PDF/dini-zertifikat-2010-3-en.pdf.

[10] European Science Foundation (ESF), Standing Committee for the Humanities (SCH) (Position Paper), 2007, available at: http://www.esf.org/research-areas/humanities.html.

[11] E. Gimenez-Toledo, C. Tejada-Artigas and J. Manana-Rodriguez, Evaluation of scientific books' publishers in social sciences and humanities: results of a survey, Research Evaluation 22(1) (2013), 64-77.

[12] K.L. Hahn, Research library publishing services: new options for University publishing, Washington DC, 2008, available at: http://www.arl.org/news/pr/research-library-publishing-services-2apr08.shtml.

[13] A. Janneke and B. Schmidt, From service providers to content producers: new opportunities for libraries in collaborative open access book publishing, New Review of Academic Librarianship 16 (2010), 28-43.

[14] J. Manana-Rodriguez and E. Gimenez-Toledo, Coverage of Spanish social sciences and humanities journals by national and international databases, IR Information Research 16(4) (2011), available at: http://informationr.net/ir/16-4/ paper506.html\#authors.

[15] C. Milloy, G. Stone and E. Collins, OAPEN-UK: an Open Access business model for scholarly monographs in the humanities and social sciences, in: Social Shaping of Digital Publishing: Exploring the Interplay Between Culture and Technology - Proceedings of the 16th International Conference on Electronic Publishing, IOS Press, Amsterdam, 2012.

[16] P. Moscati, Archeologia e Calcolatori: le ragioni di una scelta, Archeologia e Calcolatori 20 (2009), available at: http://soi.cnr.it/archcalc/indice/PDF20/12_Moscati.pdf.

[17] P. Mounier, Fremium as a sustainable economic model for open access electronic publishing in Humanities and social sciences, ELPUB2012, Social Shaping of Digital Publishing: Exploring the interplay between Culture and Technology, 16th International Conference on Electronic Publishing, Guimarães, Portugal, 14-15 June 2012.

[18] J.L. Mullins, C. Murray-Rust, J. Ogburn and R. Crow, Library publishing services: strategies for success, Research report version 1.0, Library Research Publication, Paper 136, 2011, available at: http://wp.sparc.arl.org/lps.

[19] S.E. Thomas, Publishing solutions for contemporary scholars: the library as innovator and partner, Library Hi Tech. 24(4) (2006), 563-573.

[20] UNESCO report, World social science report, 2010.

[21] J. Willinsky, Toward the design of an Open Monograph Press, Journal of Electronic Publishing 12(1) (2009), DOI: http://dx.doi.org/10.3998/3336451.0012.103. 